\title{
Negative impact of malignant effusion on osimertinib treatment for non-small cell lung cancer harboring EGFR mutation
}

\author{
Takahisa Kawamura ${ }^{1}$. Hirotsugu Kenmotsu ${ }^{1} \cdot$ Haruki Kobayashi $^{1} \cdot$ Shota Omori $^{1} \cdot$ Kazuhisa Nakashima $^{1}$. \\ Kazushige Wakuda ${ }^{1} \cdot$ Akira Ono $^{1} \cdot$ Tateaki Naito $^{1} \cdot$ Haruyasu Murakami ${ }^{1} \cdot$ Keita Mori $^{2} \cdot$ Masahiro Endo $^{3}$. \\ Toshiaki Takahashi $^{1}$
}

Received: 7 April 2019 / Accepted: 31 May 2019 / Published online: 10 June 2019

(C) The Author(s) 2019

\section{Summary}

3rd-generation epidermal growth factor receptor-tyrosine kinase inhibitors (EGFR-TKIs), including osimertinib, have reasonable efficacy in non-small-cell lung cancers (NSCLC) with EGFR mutations. However, the efficacy of osimertinib in NSCLC patients with fluids, such as pleural, pericardial and abdominal effusions, is unclear. We evaluated the efficacy of osimertinib in this specific setting. NSCLC patients harboring EGFR T790 M mutations who experienced progressive disease after first EGFR-TKI treatment and started osimertinib treatment between April 2016 and August 2018 were retrospectively screened. In particular, we assessed the efficacy of osimertinib for NSCLC with EGFR T790 M mutations in patients who were diagnosed with EGFR T790 M mutation by malignant effusion. Among 90 patients with EGFR T790 M mutation who started osimertinib treatment after EGFR-TKI failure, 21 were diagnosed from malignant effusions excluding cerebrospinal fluid (F group) and 69 using other methods including tissue biopsies (NF group). Patient characteristics were well-balanced between the two groups. Overall response was $50 \%$, and significantly worse in the F group $(29 \%)$ than the NF group $(57 \% ; P=0.025)$. Median progressionfree survival with osimertinib treatment in the F group (7.1 months, 95\% confidence interval [CI]: 2.3-14.0) was significantly shorter than that in the NF group (11.9 months, 95\% CI: 9.5-16.0; $P=0.046)$ ). Median drainage-free time was 10.9 months $(95 \%$ CI: 1.4 months- not reached). The present study showed that the efficacy of osimertinib for NSCLC in which EGFR T790 M mutation is detected by malignant effusion may be less than in EGFR T790 M-mutated NSCLC detected by other methods.

Keywords Non-small cell lung cancer $\cdot$ EGFR-TKI $\cdot$ Osimertinib $\cdot$ Malignant effusion

\author{
Takahisa Kawamura \\ takahisa1104@gmail.com \\ Hirotsugu Kenmotsu \\ h.kenmotsu@scchr.jp \\ Haruki Kobayashi \\ h.kobayashi@scchr.jp \\ Shota Omori \\ s.omori@scchr.jp \\ Kazuhisa Nakashima \\ ka.nakashima@scchr.jp \\ Kazushige Wakuda \\ k.wakuda@scchr.jp \\ Akira Ono \\ a.ono@scchr.jp \\ Tateaki Naito \\ t.naito@scchr.jp
}

Haruyasu Murakami

ha.murakami@scchr.jp

Keita Mori

ke.mori@scchr.jp

Masahiro Endo

m.endo@scchr.jp

Toshiaki Takahashi

t.takahashi@scchr.jp

1 Division of Thoracic Oncology, Shizuoka Cancer Center, 1007 Shimonagakubo, Nagaizumi-cho, Suntou-gun, Shizuoka 411-8777, Japan

2 Clinical Research Center, Shizuoka Cancer Center, 1007 Shimonagakubo, Nagaizumi-cho, Suntou-gun, Shizuoka 411-8777, Japan

3 Division of Diagnostic Radiology, Shizuoka Cancer Center, 1007 Shimonagakubo, Nagaizumi-cho, Suntou-gun, Shizuoka 411-8777, Japan 


\section{Abbreviations}

CI Confidence interval

EGFR Epidermal growth factor receptor gene

NSCLC Non-small-cell lung cancer

ORR overall response rate

PD progressive disease

PFS Progression-free survival

PS Performance status

TKI Tyrosine kinase inhibitor

\section{Introduction}

Non-small cell lung cancer (NSCLC) is a common cause of cancer-related death [1]. The identification of epidermal growth factor receptor (EGFR) as a driver oncogene has dramatically effected lung cancer treatment strategy. EGFRtyrosine kinase inhibitors (TKIs; EGFR-TKIs) have produced potent responses in patients with EGFR-mutant NSCLC [2]. However, patients with advanced NSCLC that harbor EGFR

Table 1 Patient characteristics

\begin{tabular}{|c|c|c|c|}
\hline & F group; $n=21$ & NF group; $n=69$ & $P$ \\
\hline Median age at start of osimertinib treatment & 71 & 68 & 0.28 \\
\hline (range) & $(60-84)$ & $(38-89)$ & \\
\hline Gender & & & 0.94 \\
\hline Male & 5 & 17 & \\
\hline Female & 16 & 52 & \\
\hline Smoking status & & & 0.67 \\
\hline Smoker & 9 & 26 & \\
\hline Non-smoker & 12 & 43 & \\
\hline PS at start of osimertinib treatment & & & 0.78 \\
\hline 0 & 2 & 13 & \\
\hline 1 & 13 & 37 & \\
\hline 2 & 5 & 15 & \\
\hline 3 & 1 & 4 & \\
\hline \multicolumn{4}{|l|}{ EGFR mutation } \\
\hline Exon 19 deletion & 12 & 44 & \\
\hline Exon $21 \mathrm{~L} 858 \mathrm{R}$ & 7 & 25 & \\
\hline Others & 2 & 0 & \\
\hline Surgical history & & & 0.69 \\
\hline No; Advanced (III-IV) & 17 & 53 & \\
\hline Yes; Post-surgery recurrence & 4 & 16 & \\
\hline Median previous chemotherapy regimens (range) & $3(2-12)$ & $3(2-11)$ & 0.98 \\
\hline Previous history of pleurodesis & 1 & 0 & \\
\hline \multicolumn{4}{|c|}{ Anatomical progressive disease sites after initial EGFR-TKI treatments; $n(\%)$} \\
\hline Pleural effusion/ Ascites & $14(67)$ & $6(9)$ & \\
\hline Thoracic lesion & $9(43)$ & $50(72)$ & \\
\hline Bone lesion & $3(14)$ & $16(23)$ & \\
\hline Brain lesion & $5(24)$ & $16(23)$ & \\
\hline Liver lesion & $0(0)$ & $11(16)$ & \\
\hline Others & $14(67)$ & $29(42)$ & \\
\hline \multicolumn{4}{|l|}{ Malignant effusion in radiographic assessment } \\
\hline Yes & 21 & 21 & \\
\hline No & 0 & 48 & \\
\hline Effusion thickness (mm, per computed tomography) & $n=16$ & $n=21$ & $0.0022 *$ \\
\hline Median (range) & $39(12-80)$ & $18(11-63)$ & \\
\hline
\end{tabular}

EGFR epidermal growth factor receptor; F group: patients with NSCLC in which T790 M mutation was detected by fluid samples; $N F$ group patients with NSCLC in which T790 M mutation was detected by other methods; NSCLC non-small-cell lung cancer; $P S$ performance status 
mutations develop progressive disease (PD) after a median response period of 11 months [3]. A specific point mutation within exon $20(\mathrm{~T} 790 \mathrm{M})$ accounts for $30-60 \%$ of instances of acquired resistance to EGFR-TKI [4-8]. Osimertinib, a thirdgeneration EGFR-TKI, is reportedly effective against NSCLC that harbors EGFR T790 M mutation, and was approved as a standard therapy after first EGFR-TKI failure [9-11]. However, limited information is available about its efficacy for EGFR-mutated NSCLC, especially in cases with associated body fluids, such as malignant pleural effusion, pericardial effusion, and ascites [12]. In this study, we focused on patients treated with osimertinib whose mutation status of $E G F R$ T790 M was identified by fluid samples, including pericardial, abdominal and pleural effusion.

\section{Patients and methods}

\section{Patients and EGFR mutation analysis}

We retrospectively reviewed medical records of patients diagnosed with NSCLC that harbored $E G F R$-activating mutations and who received osimertinib treatment at Shizuoka Cancer Center from April 2016 to August 2018. For eligible patients, exon $20 \mathrm{~T} 790 \mathrm{M}$ mutation was detected by tissue samples and/ or cytology samples and/or blood samples after the failure of at least one EGFR-TKI treatment. EGFR-activating mutations included exon 18 G719X mutation, exon 19 deletions, exon 20 S768I mutation, exon 21 L858R mutation, and exon 21 L861Q mutation. Patients with T790 M mutation detected in cerebrospinal fluid were excluded from our analyses because the emergence of T790 $\mathrm{M}$ in central nervous system is rare

Table 2 Overall responses

\begin{tabular}{lllllll}
\hline & \multicolumn{2}{l}{ F group; $n=21$} & & \multicolumn{2}{l}{ NF group; $n=69$} & \multirow{2}{*}{$P$} \\
\cline { 2 - 3 } & $n$ & $\%$ & & $n$ & $\%$ & \\
\hline CR & 0 & 0 & & 0 & 0 & \\
PR & 6 & 29 & & 39 & 57 & \\
SD & 6 & 29 & & 20 & 29 & \\
PD & 5 & 23 & & 5 & 7 & \\
NE & 4 & 19 & & 5 & 7 & \\
ORR & & 29 & & 57 & $0.03 *$ \\
DCR & & 58 & & & 86 & $0.02 *$ \\
PD rate & & 23 & & 7 & $0.02 *$ \\
\hline
\end{tabular}

$C R$ complete response; $D C R$ disease control rate; $F$ group patients with NSCLC in which T790 M mutation was detected by fluid samples; $N E$ not evaluated; NF group patients with NSCLC in which T790 M mutation was detected by other methods; $O R R$ overall response rate; $P D$ disease progression; $P R$ partial response; $S D$ stable disease compared with other lesions, and leads to uncommon prognosis [13]. We assessed patient characteristics, efficacy of osimertinib including overall response rate (ORR), and progression-free survival (PFS). Efficacy data were compared between two subgroups: (a) patients in whom T790 M mutation was detected via malignant effusions vs other specimen types, including plasma samples; and (b) patients with vs without malignant effusion, based on radiographic evaluation. PFS was defined as the period from the date of initial osimertinib treatment to the date of PD. Duration of drainage-free time was defined as the date of initial osimertinib treatment to the day of next drainage time, because of symptoms such as dyspnea. For radiographic evaluation of malignant effusion, massive effusion detectable by chest radiograph (requiring drainage) or effusion of $\geq 10 \mathrm{~mm}$ thickness at computed tomography, were defined as third space fluid accumulation (patients with effusions), as previously reported [14]. We used Cobas EGFR Mutation Test kits version 2 in $E G F R$ mutation analyses of tissue and cytology samples.

\section{Statistical analysis}

Statistical analysis was performed using JMP 10 software (SAS Institute, Inc., Cary, NC, USA). Univariate analyses, using chi-squared and Mann-Whitney $U$ tests, were used to evaluate differences in efficacy between the group in whom EGFR T790 M mutation was detected by fluid samples, and the group that used non-fluid samples. $P<0.05$ was considered significant. This study was approved by the institutional review board of Shizuoka Cancer Center.

\section{Results}

\section{Patient characteristics}

We screened 92 patients with NSCLC who started osimertinib treatment after EGFR-TKI failure between April 2016 and August 2018. Among these patients, EGFR T790 M mutation was detected in 23 patients via body fluids (19 pleural effusion, 2 ascites, and 2 cerebrospinal fluid), and in 69 patients in other specimen types, such as primary lesions, lymph node metastases, other tissue samples and plasma samples. Two patients in whom T790 M mutation was detected by cerebrospinal fluid (other effusions were not identified radiographically in both the cases) were excluded from the analysis. Therefore, 21 T790 M-positive patients detected by fluid samples (F group) and 69 T790 M-positive patients detected by non-fluid samples (NF group) were analyzed in this study. Baseline patient characteristics (age at initiation of osimertinib 
treatment, gender, smoking status, performance status [PS], EGFR mutation type, surgical history, and number of previous chemotherapy regimens) are shown in Table 1 . The Median age was 71 (range; 60-84) in F group and 68 (range; 38-89) in NF group, respectively. Patient characteristics were wellbalanced between two groups. $\mathrm{F}$ group included two cases of uncommon mutations (compound mutation of ex18 G719X and ex20 S768I); the NF group did not. 5 patients in $\mathrm{F}$ group had massive effusion detectable just by chest radiograph, and 85 patients (16 in $\mathrm{F}$ group and 69 in NF group) were available for computed tomographic assessment immediately before osimertinib treatment. In the computed tomography, the effusion was identified in $16 \mathrm{~F}$ group patients and in 21 of $69 \mathrm{NF}$ group patients. Median effusion thickness at computed tomography significantly differed between the $\mathrm{F}$ group (39 mm, range: $12-80)$ and the NF group (18 mm, range: $11-63 ; P=0.0022)$. The previous history of pleurodesis was found in one case in the $\mathrm{F}$ group. Anatomical sites of progression after initial EGFR-TKI treatment are also shown in Table 1.The most common progressive
Fig. 1 a Progression-free survival curves for osimertinib-treated patients with non-small-cell lung cancer that harbors $\mathrm{T} 790 \mathrm{M} \mathrm{mu}-$ tation, which was detected in fluid samples (F group) or through other methods

(NF group). b Comparison of progression-free survival curve of osimertinib-treated patients with or without effusions, based on radiographic evaluation
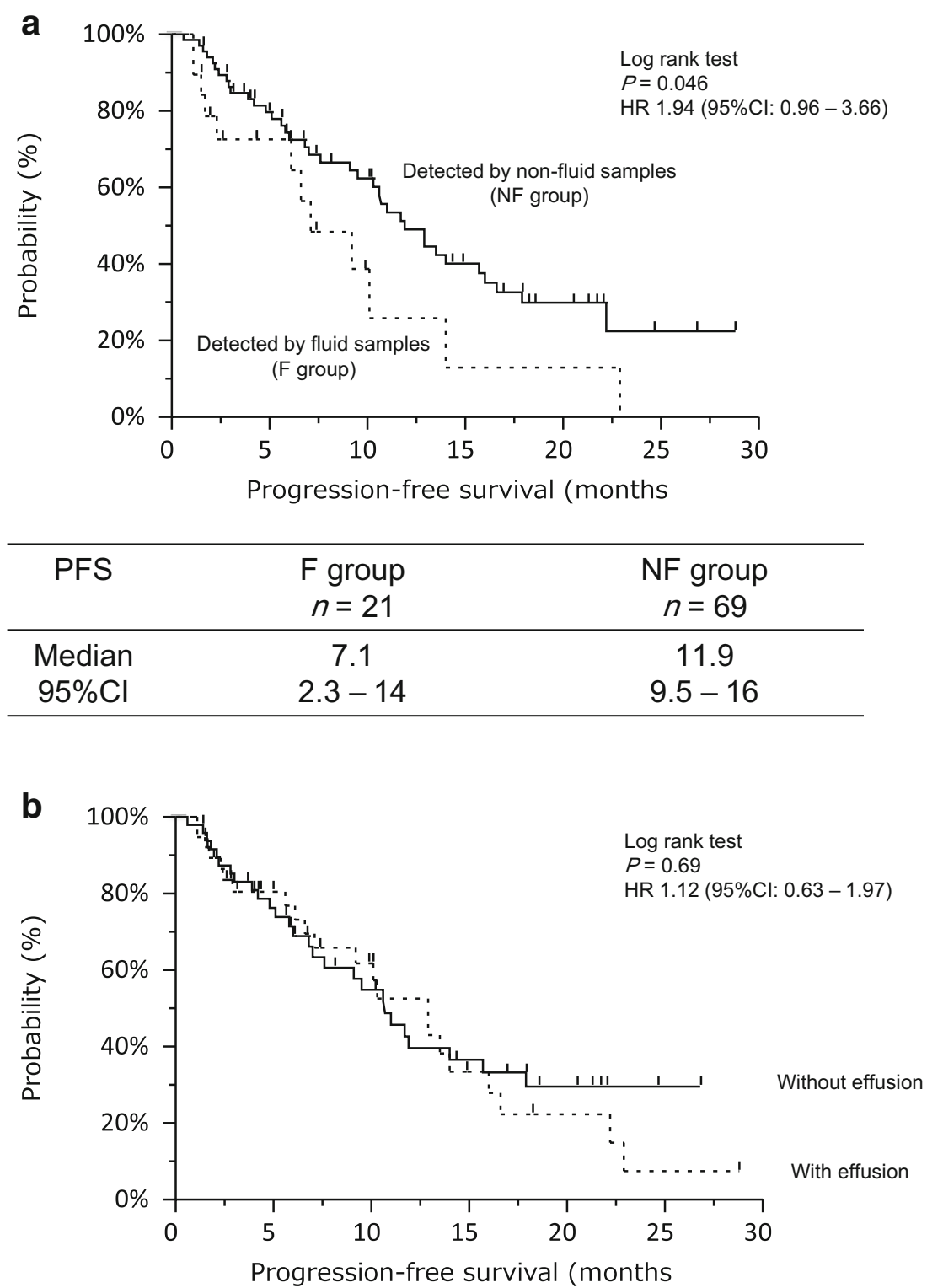

\begin{tabular}{ccc}
\hline PFS & $\begin{array}{c}\text { With effusion } \\
n=42\end{array}$ & $\begin{array}{c}\text { Without effusion } \\
n=48\end{array}$ \\
\hline Median & 12.9 & 10.7 \\
$95 \% \mathrm{Cl}$ & $7.1-16$ & $6.8-15.7$ \\
\hline
\end{tabular}


Fig. 2 Drainage-free time curve of osimertinib-treated patients with non-small-cell lung cancer that harbors T790 M mutation, which was detected in fluid samples (F group)

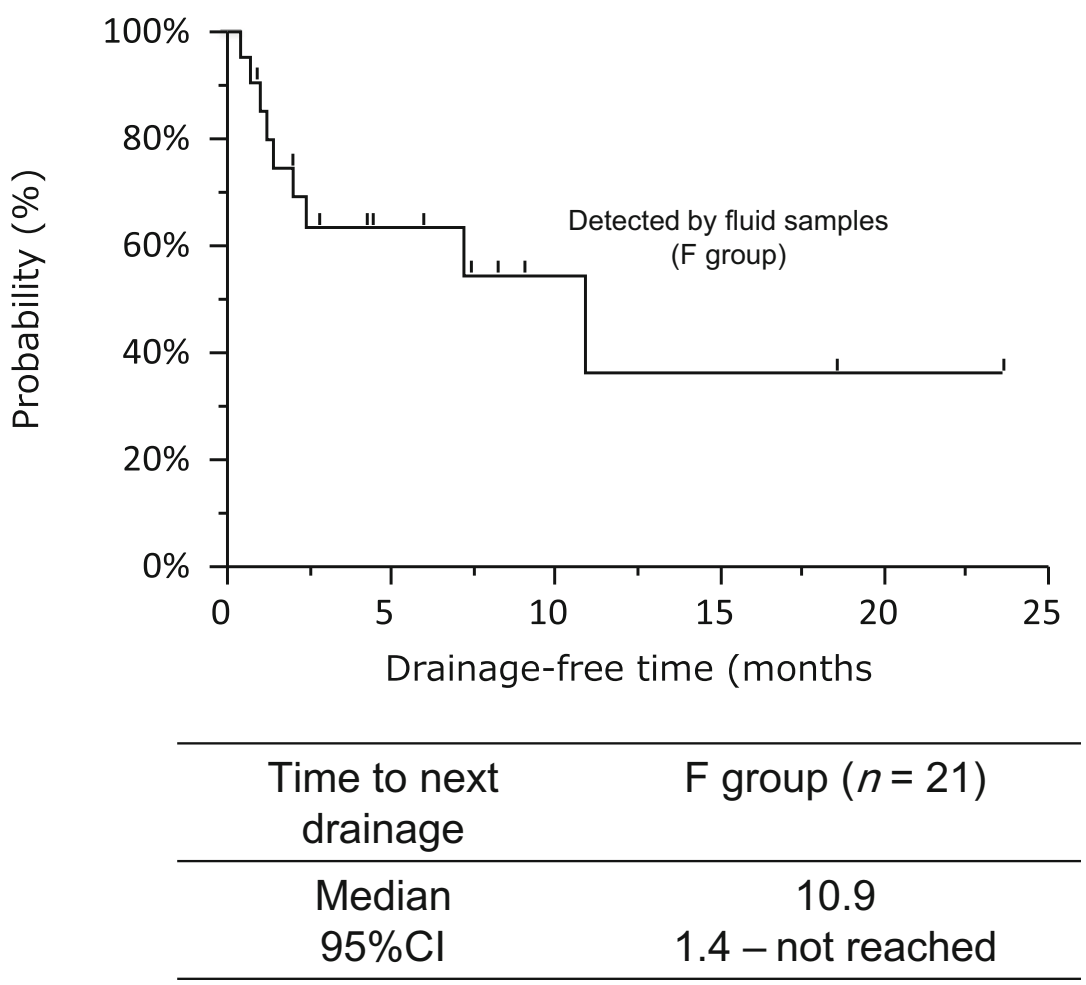

lesion after initial EGFR-TKI treatment (gefitinib, erlotinib, and afatinib) in the $\mathrm{F}$ group was malignant effusion: $67 \%(n=14)$, in contrast to $9 \%(n=6)$ in NF group.

\section{Efficacy}

Objective responses are shown in Table 2. Overall response was significantly worse in F group than in NF group (29\% vs $57 \%, P=0.025)$. Furthermore, median PFS with osimertinib treatment was significantly shorter in $\mathrm{F}$ group (7.1 months [95\% confidence interval (CI): 2.3-14.0]) than in NF group (11.9 months [95\% CI: 9.5-16.0]; $P=0.046$; Fig. 1a). However, PFS did not significantly differ between patients with effusions (12.9 months [95\% CI: 7.1-16.0]) and without effusions (10.7 months [95\% CI: 6.8-15.7]; $P=0.69$; Fig. 1b). In the $\mathrm{F}$ group, median drainage-free time was 10.9 months (95\% CI: 1.4 months-not reached; Fig. 2).

\section{Progression pattern}

Anatomical progressive disease sites after osimertinib treatment are shown in Table 3 . In the F group, the most common progressive lesion following osimertinib treatment was malignant effusion at $43 \%(n=9)$, in contrast to $10 \%(n=7)$ in NF group.

\section{Post-progression therapy}

By the cutoff date, 9 (43\%) of T790 M-positive patients in the F group and 33 (48\%) in the NF group had not experienced disease progression after initiating osimertinib. Similarly, 6 patients $(28 \%)$ in the $\mathrm{F}$ group and 13 patients $(19 \%)$ in the NF group did not receive subsequent chemotherapy after osimertinib failure. Post-progression therapy after osimertinib failure is shown in Table 4. Among patients who could receive
Table 3 Anatomical progressive disease sites after osimertinib treatment

\begin{tabular}{lll}
\hline & F group; $n=21$ & NF group; $n=69$ \\
\hline Anatomical progressive disease sites after osimertinib treatment & $n(\%)$ & $n(\%)$ \\
Pleural effusion/ Ascites & $9(43)$ & $7(10)$ \\
Thoracic lesion & $5(24)$ & $20(29)$ \\
Bone lesion & $0(0)$ & $2(3)$ \\
Brain lesion & $3(14)$ & $8(12)$ \\
Liver lesion & $1(5)$ & $6(9)$ \\
Others & $4(19)$ & $14(20)$ \\
Not evaluated & $7(33)$ & $33(48)$ \\
\hline
\end{tabular}


Table 4 Post-progression therapies

\begin{tabular}{|c|c|c|c|c|}
\hline & \multicolumn{2}{|c|}{ F group; $n=21$} & \multicolumn{2}{|c|}{ NF group; $n=69$} \\
\hline & $n$ & $\%$ & $n$ & $\%$ \\
\hline Continuation of osimertinib & 9 & 42 & 33 & 48 \\
\hline Cessation of osimertinib due to toxicity & 1 & 5 & 2 & 3 \\
\hline EGFR-TKIs & 0 & 0 & 1 & 1 \\
\hline Platinum doublet & 2 & 10 & 8 & 12 \\
\hline Single non-platinum & 1 & 5 & 4 & 6 \\
\hline Non-platinum + angiogenesis inhibitor & 0 & 0 & 4 & 6 \\
\hline Immune checkpoint inhibitors & 1 & 5 & 3 & 4 \\
\hline Investigational drugs & 1 & 5 & 1 & 1 \\
\hline BSC & 6 & 28 & 13 & 19 \\
\hline
\end{tabular}

$B S C$ best supportive care; $E G F R$-TKI epidermal growth factor receptor-tyrosine kinase inhibitor; $F$ group patients with NSCLC in which T790 M mutation was detected by fluid samples; NF group patients with NSCLC in which T790 M mutation was detected by other methods post-progression therapy, the most common regimen was platinum-doublet chemotherapy, for both groups.

\section{Discussion}

We conducted this retrospective study with the aim of evaluating osimertinib efficacy for patients with malignant effusions. Reportedly, osimertinib is efficacious for patients with $E G F R$-activating mutations, and is especially promising for those with central nervous system metastases. However, its efficacy toward fluid lesions such as malignant pleural and pericardial effusions, and ascites, has not been widely studied, though patients often suffer from symptoms such as dyspnea due to malignant effusions despite osimertinib treatment. A previous study reported that osimertinib monotherapy is less effective in patients with NSCLC with pleural effusions [12]. However, evidence is still scanty, as previous studies have been retrospective in design with small study cohorts. In the present study, median PFS did not significantly differ between patients with and without effusions: more appropriate evaluation of effusions (including the presence of malignancy and/or thickness in computed tomography) is needed in the analysis, although it is feasible only through prospective studies. The present study revealed that the median PFS in osimertinibtreated patients whose T790 M-positive status was detected by fluid samples was significantly shorter than if detected by non-fluid samples. Similarly, overall response in the F group was significantly worse than in NF group. One possible explanation involves osimertinib penetration to third space. As for other EGFR-TKIs, Masago et al. investigated the pharmacokinetics of erlotinib in NSCLC with malignant pleural effusion, and found repeated erlotinib dosing led to significant accumulating drug concentrations in malignant effusions, with the mean percentage of erlotinib penetration from plasma to pleural effusion to be $18 \%$ on Day 1 and $112 \%$ on Day 8 [15]. However, penetration from plasma to pleural effusion for osimertinib may be low, unlike erlotinib. Therefore, greater understanding of the pharmacokinetics or pharmacodynamics of osimertinib is critical. We are therefore conducting a prospective study that evaluates the association of malignant effusion with osimertinib exposure in NSCLC (UMIN000028922).

Another explanation concerns effusion quantity. In the present study, median effusion thicknesses at computed tomography in $\mathrm{F}$ group were greater than in NF group, and median PFS with osimertinib treatment in $\mathrm{F}$ group was significantly shorter than in NF group. On the other hand, PFS did not differ between patients with and without effusions by radiographic assessment. It suggests that negative impact of osimertinib efficacy may be due to the quantity of malignant effusions, not due to the radiographic presence of malignant effusions. However, cutoff values of the quantity remain unclear.

Our study showed that median drainage-free time was 10.9 months. This suggests that osimertinib has a certain efficacy in the management of effusion despite poor response rate in patients with malignant effusion.

This study has some limitations. First, despite the inclusion of larger-scale data than previous studies, it is limited by its retrospective design. Second, data were obtained from patients at a single institution. Finally, not all effusions detected radiologically in both $\mathrm{F}$ group and NF group were confirmed as T790 $\mathrm{M}$ positive in this study.

In conclusion, efficacy for osimertinib treatment in patients with EGFR T790 M mutations that were detected via malignant effusion may be limited compared with previous reports. An analysis with a larger cohort is needed to validate the results in this study. 
Funding This research received no specific grant from funding agencies in the public, commercial, or not-for-profit sectors.

\section{Compliance with ethical standards}

Conflict of interest Haruyasu Murakami has received honoraria from Boehringer Ingelheim, Pfizer, Chugai Pharma, Taiho Pharmaceutical, AstraZeneca, Eli Lilly, Ono Pharmaceutical, Bristol-Myers Squibb, Novartis. Haruki Kobayashi has received honoraria from Eli Lilly and Taiho Pharmaceutical. Kazuhisa Nakashima has received honoraria from Chugai Pharma, Boeringer Ingelheim and Novartis Pharma. Shota Omori has received personal fees from MSD K.K., Chugai Pharmaceutical, Boeringer Ingelheim, Ono Pharmaceutical, Taiho Pharmaceutical, and AstraZeneca. Kazushige Wakuda has received honoraria from AstraZeneca, Chugai Pharmaceutical, Boeringer Ingelheim, Eli Lilly, Taiho Pharmaceutical, Ono Pharmaceutical, and has received grant from AstraZeneca. Akira Ono has received honoraria from Chugai Pharmaceutical, Taiho Pharmaceutical, Ono Pharmaceutical, MSD K.K., Boehringer Ingelheim, and Novartis. Hirotsugu Kenmotsu has received honoraria from AstraZeneca, Chugai Pharmaceutical, BristolMyers, Boeringer Ingelheim, Eli Lilly, Kyowa Hakko Kirin, MSD K.K., Novartis Pharma, and grants from AstraZeneca, Chugai Pharmaceutical and Boehringer Ingelheim. Tateaki Naito has received honoraria from Ono Pharmaceutical. Masahiro Endo has received honoraria from AstraZeneca and Ono Pharmaceutical. Toshiaki Takahashi has received honoraria from Eli Lilly, AstraZeneca, Chugai Pharma, MSD, Ono Pharmaceutical, Roche Diagnostics, Boehringer Ingelheim, Pfizer and grants from Eli Lilly, AstraZeneca, Chugai Pharma, MSD, Pfizer and Ono Pharmaceutical. For the remaining authors no conflict interested are declared. All of the conflict of interest is outside the submitted work.

Statement of ethics All procedures performed in studies involving human participants were in accordance with the ethical standards of the institutional research committee and with the 1964 Helsinki declaration and its later amendments.

Open Access This article is distributed under the terms of the Creative Commons Attribution 4.0 International License (http:// creativecommons.org/licenses/by/4.0/), which permits unrestricted use, distribution, and reproduction in any medium, provided you give appropriate credit to the original author(s) and the source, provide a link to the Creative Commons license, and indicate if changes were made.

\section{References}

1. Siegel R, Naishadham D, Jemal A (2012) Cancer statistics, 2012. CA Cancer J Clin 62(1):10-29. https://doi.org/10.3322/caac.20138

2. Mok TS, Wu YL, Thongprasert S, Yang CH, Chu DT, Saijo N, Sunpaweravong P, Han B, Margono B, Ichinose Y, Nishiwaki Y, Ohe Y, Yang JJ, Chewaskulyong B, Jiang H, Duffield EL, Watkins CL, Armour AA, Fukuoka M (2009) Gefitinib or carboplatinpaclitaxel in pulmonary adenocarcinoma. N Engl J Med 361(10): 947-957. https://doi.org/10.1056/NEJMoa0810699

3. Maemondo M, Inoue A, Kobayashi K, Sugawara S, Oizumi S, Isobe H, Gemma A, Harada M, Yoshizawa H, Kinoshita I, Fujita Y, Okinaga S, Hirano H, Yoshimori K, Harada T, Ogura T, Ando M, Miyazawa H, Tanaka T, Saijo Y, Hagiwara K, Morita S, Nukiwa T, North-East Japan Study G (2010) Gefitinib or chemotherapy for nonsmall-cell lung cancer with mutated EGFR. N Engl J Med 362(25):2380-2388. https://doi.org/10.1056/NEJMoa0909530

4. Yu HA, Arcila ME, Rekhtman N, Sima CS, Zakowski MF, Pao W, Kris MG, Miller VA, Ladanyi M, Riely GJ (2013) Analysis of tumor specimens at the time of acquired resistance to EGFR-TKI therapy in 155 patients with EGFR-mutant lung cancers. Clin Cancer Res 19(8):2240-2247. https://doi.org/10.1158/1078-0432. CCR-12-2246

5. Chouaid C, Dujon C, Do P, Monnet I, Madroszyk A, Le Caer H, Auliac JB, Berard H, Thomas P, Lena H, Robinet G, Baize N, Bizieux-Thaminy A, Fraboulet G, Locher C, Le Treut J, Hominal S, Vergnenegre A (2014) Feasibility and clinical impact of rebiopsy in advanced non small-cell lung cancer: a prospective multicenter study in a real-world setting (GFPC study 12-01). Lung Cancer 86(2):170-173. https://doi.org/10.1016/j.lungcan.2014.08. 016

6. Kuiper JL, Heideman DA, Thunnissen E, Paul MA, van Wijk AW, Postmus PE, Smit EF (2014) Incidence of T790M mutation in (sequential) rebiopsies in EGFR-mutated NSCLC-patients. Lung Cancer 85(1):19-24. https://doi.org/10.1016/j.lungcan.2014.03. 016

7. Kawamura T, Kenmotsu H, Taira T, Omori S, Nakashima K, Wakuda K, Ono A, Naito T, Murakami H, Mori K, Nakajima T, Ohde Y, Endo M, Takahashi T (2016) Rebiopsy for patients with non-small-cell lung cancer after epidermal growth factor receptortyrosine kinase inhibitor failure. Cancer Sci 107(7):1001-1005. https://doi.org/10.1111/cas.12963

8. Ko R, Kenmotsu H, Serizawa M, Koh Y, Wakuda K, Ono A, Taira T, Naito T, Murakami H, Isaka M, Endo M, Nakajima T, Ohde Y, Yamamoto N, Takahashi K, Takahashi T (2016) Frequency of EGFR T790M mutation and multimutational profiles of rebiopsy samples from non-small cell lung cancer developing acquired resistance to EGFR tyrosine kinase inhibitors in Japanese patients. BMC Cancer 16(1):864. https://doi.org/10. 1186/s12885-016-2902-0

9. Janne PA, Yang JC, Kim DW, Planchard D, Ohe Y, Ramalingam SS, Ahn MJ, Kim SW, Su WC, Horn L, Haggstrom D, Felip E, Kim JH, Frewer P, Cantarini M, Brown KH, Dickinson PA, Ghiorghiu S, Ranson M (2015) AZD9291 in EGFR inhibitor-resistant nonsmall-cell lung cancer. N Engl J Med 372(18):1689-1699. https:// doi.org/10.1056/NEJMoa1411817

10. Goss G, Tsai CM, Shepherd FA, Bazhenova L, Lee JS, Chang GC, Crino L, Satouchi M, Chu Q, Hida T, Han JY, Juan O, Dunphy F, Nishio M, Kang JH, Majem M, Mann H, Cantarini M, Ghiorghiu S, Mitsudomi T (2016) Osimertinib for pretreated EGFR Thr790Metpositive advanced non-small-cell lung cancer (AURA2): a multicentre, open-label, single-arm, phase 2 study. Lancet Oncol 17(12):1643-1652. https://doi.org/10.1016/S1470-2045(16) 30508-3

11. Mok TS, Wu YL, Ahn MJ, Garassino MC, Kim HR, Ramalingam SS, Shepherd FA, He Y, Akamatsu H, Theelen WS, Lee CK, Sebastian M, Templeton A, Mann H, Marotti M, Ghiorghiu S, Papadimitrakopoulou VA, Investigators A (2017) Osimertinib or platinum-Pemetrexed in EGFR T790M-positive lung Cancer. N Eng1 J Med 376(7):629-640. https://doi.org/10.1056/ NEJMoa1612674

12. Masuhiro K, Shiroyama T, Suzuki H, Takata SO, Nasu S, Takada H, Morita S, Tanaka A, Morishita N, Okamoto N, Hirashima T (2018) Impact of pleural effusion on outcomes of patients receiving Osimertinib for NSCLC harboring EGFR T790M. Anticancer Res 38(6):3567-3571. https://doi.org/10.21873/ anticanres. 12629

13. Hata A, Katakami N, Yoshioka H, Takeshita J, Tanaka K, Nanjo S, Fujita S, Kaji R, Imai Y, Monden K, Matsumoto T, Nagata K, Otsuka K, Tachikawa R, Tomii K, Kunimasa K, Iwasaku M, Nishiyama A, Ishida T, Nishimura Y (2013) Rebiopsy of nonsmall cell lung cancer patients with acquired resistance to epidermal growth factor receptor-tyrosine kinase inhibitor: comparison between T790M mutation-positive and mutation-negative 
populations. Cancer 119(24):4325-4332. https://doi.org/10.1002/ cncr.28364

14. Ryu JS, Ryu HJ, Lee SN, Memon A, Lee SK, Nam HS, Kim HJ, Lee KH, Cho JH, Hwang SS (2014) Prognostic impact of minimal pleural effusion in non-small-cell lung cancer. J Clin Oncol 32(9): 960-967. https://doi.org/10.1200/JCO.2013.50.5453

15. Masago K, Togashi Y, Fukudo M, Terada T, Irisa K, Sakamori Y, Kim YH, Mio T, Inui K, Mishima M (2011) Plasma and pleural fluid pharmacokinetics of erlotinib and its active metabolite OSI-
420 in patients with non-small-cell lung cancer with pleural effusion. Clin Lung Cancer 12(5):307-312. https://doi.org/10.1016/j. cllc.2011.06.004

Publisher's note Springer Nature remains neutral with regard to jurisdictional claims in published maps and institutional affiliations. 